\title{
PROPOSTA PARA O ENSINO DA PARASITOLOGIA MÉdica PóS CURSO BÁSICO
}

\author{
Dalva A. Mello *
}

\section{INTRODUÇÃO}

A aprendizagem como resultado do processo de ensinar depende de uma série de fatores interligados, como: motivação, capacidade, experiência prévia, percepção de relações pertinentes, busca ativa de significados, comunicação de resultados, aplicação etc.

Numa pesquisa realizada sobre problemas de ensino (3) verificou-se que as relações entre aprendizagem $\mathrm{e}$ os sentidos dependiam das seguintes proporções: $1 \%$ paladar, $1,5 \%$ tato, $3,5 \%$ audição e $83 \%$ visão. A memorização alcançava seus resultados quando se relembravam $10 \%$ do que era lido, $20 \%$ do que era ouvido, $30 \%$ do que era visto, $50 \%$ do que era ouvido e visto, $70 \%$ do que era falado e $90 \%$ do que era realizado. Tudo isso significa, em sintese, que qualquer conhecimento a ser transmiticio deve ser oferecido de forma dinâmica e que o estudante tenha alto grau de participação no processo. "Aprender é modificar o comportamento por meio de treino ou de experiência".

A aprendizagem no ensino médico está diretamente relacionada a uma série de habilidades: de resolução de problemas, de percepção, de ordem psico-motora, de transformação de atituces face a valores profissionais e sociais etc. Portanto, é uma aprendizagem complexa e que depende para sua manutenção de treino constante e continuado.
A elaboração de um programa de $\mathrm{Pa}$ rasitologia Pós Curso Básico, destinado especialmente a curso de Medicina, torna-se justificável principalmente pelo fato pedagógico de que qualquer corpo de conhecimento, para que possa ser retido pelo aluno, deve estar aplicado a um esquema de ação imeàiata. o ensino do conteúdo de parasitologia não deixa de ser complexo, pois seus objetivos educacionais correspondem a diferentes tipos de aprendizagem. Portanto, após a fase inicial de aquisição (ensino dio ICB), ele deve ser reprogramado e continuado em níveis crescentes de complexidade, a fim de que este conhecimento não seja esquecido pela "Lei do Desuso", pois quanto mais recente for o condicionamento tanto mais forte ele será (Lei da recēncia dos behavioristas) (1).

\section{PLANOS DE INTEGRAÇÃO DA PARASITOLOGIA}

A integração do ensino de Parasitologia no curso de Medicina, como de outras disciplinas, deverá ser feita em duas posições:

\section{1 - Integração Vertical}

Esta posição visa basicamente a que qualquer conhecimento parasitológico seja transmitido e ensinado em sentido vertical, isto é, ao longo do curso médico. O - Depto. Medicina Complementar - Faculdade de Ciências da Saúde - Universidade de Brasilia.
Recebido para publicaçâo em 7-2-1975. 
assunto deverá ser abordado de forma mais completa, interessando mais que o conteúdo, seja informado qualitativamente do que quantitativamente.

\section{2 - Integração Horizontal}

Este tipo de integração requer que a Parasitologia seja ensinada integrando-se em diferentes disciplinas. Para isto é necessário que os professores de Parasitologia se entrosem em todos os departamentos existentes na Faculdade. O conhecimento deste conteúdo deverá ser transmitido concomitantemente dentro dos programas das disciplinas, nas quais o enfoque parasitológico seja suscitado.

\section{FINALIDADES}

O tipo de conhecimento em Parasitologia a ser oferecido ao curso de Medicina deve ter como finalidade a procura de soluções que atendam às patologias prevalentes na região a que se destina o contingente de profissionais médicos formados pela Universidade. Para isto, como ficou bem definido pelo comitê para o ensino de Parasitologia na América Latina (2), um grupo de pessoas de diferentes especialidades poderá contribuir conjuntamente para transmitir os ensinamentos que deverão solucionar estes problemas. Isto significa que o conteúdo da Parasitologia não deverá ser transmitido apenas pelo parasitologista, porém, por uma equipe de especialistas de áreas correlatas, como a patologia clínica, imunologia, epidemiologia etc. Este conteúdo deve ser transmitido ao estudante de medicina quando sua aprendizagem puder ser posta imediatamente em ação; é necessário que tome parte e se desenvolva ao longo de todo o curso.

Deve ser oferecido dinamicamente, isto é, através de trabalhos em equipe de laboratório e de campo. O professor deverá participar da transmissão deste corpo de conhecimento como orientador dinâmico e ativo. Ao estudante caberá a responsabilidade e independência na participação ativa no desenvolvimento das tarefas programadas.

\section{NIVEIS DE ATUAÇÃO}

Propõe-se no presente artigo que o ensino da Parasitologia Médica Pós-Curso
Básico seja objetivamente desenvolvido em três niveis:

\section{$10^{\circ}$ NIVEL}

\section{Contato com a população humana}

Neste nivel o conhecimento deve ser oferecido com base em diagnósticos de laboratório, epidemiologia e prevenção das parasitoses prevalentes. $O$ aluno deverá ter intensa atividade de campo.

\section{2. ${ }^{\circ}$ NIVEL}

\section{Contato com o doente}

Neste nível, o conhecimento deve ser oferecido a partir de casos de ambulatórios ou enfermarias, com base em diagnósticos clínicos de laboratório, estudos clínico-epidemiológicos, patogenia, sintomatologia.

\section{NfVEL}

\section{Formação de Capacitação Profissional}

Neste nivel, o conhecimento de Parasitologia deve ser oferecido de maneira tal que desenvolva no aluno critérios e responsabilidades frente à análise de resultados de exames de laboratório, capacidade de seleção de exames de laboratório adequados, critérios de diagnósticos clínicos e ce laboratório.

É evidente que a formulação dos objetivos da Parasitologia Médica como um corpo de conhecimento dentro do curso de Medicina deverá atender e utilizar racionalmente os recursos existentes, de modo a conseguir maior adequação e mais alta qualidade. Antes de se definirem os objetivos, deve ser verificado previamente quais as disciplinas que oferecem condições e aceitação necessárias, para que 0 aluno pcssa trabalhar e manipular os conhecimentos de Parasitologia dentro dos três níveis propostos acima. As Faculdades de Medicina têm ảiferentes currículos. Entretanto, de uma maneira geral, constam nos seus programas disciplinas em que a Parasitologia faz parte de uma forma ou de outra de seus conteúdos, como por exemplo Medicina Comunitária, Doenças Infecciosas e Parasitárias. 


\section{CONTEƯDO PROGRAMÁTICO}

o importante é que o ensino da Parasitologia Médica, em continuação ao ICB, seja transmitido a um nível de complexidade e profundidade tais que inculquem no estudante um raciocínio que o obrigue, partindo de um conjunto de proposiçōes básicas, a inferir principios que expliquem uma série de fatos ou fenômenos. As experiências adquiridas longitudinalmente devem lhes dar capacidade de analisar problemas novos. O conteúdo a ser oferecido deve enfatizar principalmente a multicausalidade das doenças parasitárias sob um conceito ecológico. Deve ser transmitido obedecendo a critérios que sirvam de base para responcier a porquês de fenômenos, tendo ampla aplicação com enfoque prioritário nos fatores que condicionam a doença vinculado a medidas preventivas Sugere-se para isto que esta informática abranja os seguintes tópicos:

1. O equilibrio e desequilíbrio biológico HOMEM-PARASITO ,face às condições do ambiente:

- Fatores biológicos

- Fatores sócio-econômicos

- Fatores físico-químicos

2. Estudos de Epidemiologia das Parasitoses Prevalentes:

— Distribuição geográfica

- Distribuição etária
- Distribuição por sexo

- Prevalência

- Morbidade

- Mortalidade

- Fatores que condicionam a distribuição

- Importância econômica

3. Medidas Preventivas das Parasitoses Prevalenies

4. Tratamento das Parasitoses Prevalentes:

- Tratamento em termos de população

- Tratamento em termos de indivíduo

5. Relação intima HOSPEDEIRO-PARASITO a nivel imunológico, patogenia, manifestações clínicas

6. Critérios Diagnósticos:

- Parasitológico

- Imunológico

7. Critérios de Seleção e Interpretação de Exames:

- Clínico

- Laboratório

\section{REFERÊNCIAS BIBLIOGRÁFICAS}

1. CARVAlHo, I.M. - "O Processo Didático". Fundacão Getúlio Vargas. Rio de Janeiro - GB, 1973.

2. "Enseñanza de la Parasitologia en las Escuelas de Medicina de la America Latina. Primer Informe del Comité de
Expertos de la OPS/OMS" - Educ. Med. y Sal., 7: 209, 1973.

3. McCULLOCH, W.F. - "Metodos de aprendizage en el proceso aprendizage-enseñanza”. Educ. Med. Sal., 6:295, 1972 . 